\title{
Web Based Smart Metering
}

\author{
Kajal Mahure ${ }^{1}$, Komal Hirudkar ${ }^{2}$, Sakshi Manmode $^{3}$, Tushar Choudhari ${ }^{4}$, Aman Morghade $^{5}$, \\ Mahendra Nakade ${ }^{6}$
}

\author{
${ }^{1-6}$ Student, Electrical Engineering Department, Yeshwantrao Chavan College of Engineering, Nagpur
}

Received on: 15 April,2021, Revised on: 12May, 2021, Published on: 14 May, 2021

\begin{abstract}
The energy demand all over the world is increasing and hence it is necessary to reduce the energy wastage with proper metering. A Smart meter has immense application in the distribution field to monitor the energy consumption of consumers. For sustainable development, proper energy demand management is required. Until now, different methods are used to accurately calculate the requirements of energy that are yet to come. The webbased system provides the interface for monitoring with significant advantages while communicating with the household requires that they should know about the extra energy they have been using and control it accordingly. This paper also concentrates on approximately estimating the energy needs for a particular area and plan future expansion accordingly based platform plays an important role in the monitoring of the meter and it is done in realtime which is its most prominent feature. Infrastructure in real-time. The web-based platform with the help of IoT is established for recording real-time meter readings. The data visualization with the help of various graphs and charts is done to make the front end more interactive and helpful.
\end{abstract}

\section{I- INTRODUCTION}

A smart meter is an electronic device that is used to record information such as consumption of electric energy, voltage levels, current, etc. in our project we solely concentrate on monitoring the consumption of electric energy. one of the most prominent advantages of smart meters is that they communicate the information to the consumer, and with clarity of consumption behaviour, they can conserve the surplus energy they consume. Distribution companies can also benefit from it by monitoring malpractices in the system and customer billing. With the world going towards digitization, we propose an easy and handy way of tracking the electrical consumption of an average household or enterprise by developing a web-based application. Our major objective is to extract the data from the household energy meters and display it on any digital media like smartphones or personal computers. Our project can provide easy monitoring of our energy usage and spending using an in-home display. Smart Metering technologies have several different components which may vary according to the specific requirements in various horizons in the market, but the majority include the following features: Accurate measurement and real-time output. And has a huge future scope which is discussed in further sections of this paper.

There is a need of recording energy consumption data in real-time which can help us monitor the consumption of electricity of a particular area, state, or whole nation with just one click. This will enable not only the end-user but also the energy distributer to monitor energy consumption. Recording the bills of end consumer requires a lot of manpower and isn't as efficient, so we were looking for a solution which can do the same job with more ease and more accuracy. 


\section{International Journal of Innovations in Engineering and Science, www.ijies.net}

Conservation of energy is a crucial step to move towards sustainable development. With the ever-increasing demand for electric energy the gap between the demand and supply is also constantly increasing and to meet that increasing demand the focus is not only on the part where the production increases but also on how we can save as much energy as possible. Web-based smart metering helps us to conserve energy and has a promising future scope.

\section{II- PROPOSED ENERGY CONSUMPTION MONITORING SYSTEM}

Monitoring of energy is done and projected on digital media which helps in better understanding of consumption which in turn helps in saving surplus consumption and becomes cost-effective for the consumer.

\subsection{Hardware description}

Electronic energy meters in households these days are based on Digital Micro technology and they have no moving parts in them. The application-specified integrated circuit (ASIC) is the IC constructed using embedded system technology for specific purposes. They are preferred over conventional meters because they have Better accuracy, Low current performance, Low voltage performance, Difficult to temper and have a digital display. There are 4 LEDs in an electronic energy meter which are:

N OK LED ON Phase and Neutral

OK E / L LED OFF Earthing current

LED ON Earth leakage and current loss

Imp / kWh LED Blinks to show Impulses per Kilo Watt Hour.

The led who concerns this project is the Imp/kWh led which blinks 3200 times per $\mathrm{kWh}$ consumed is a standard measurement unit in an electrical measurement system one $\mathrm{kWh}$ is commonly called as one unit whose monetary value is 7-8 Rs, it varies with the consumption. If the $\mathrm{imp} / \mathrm{kWh}$ led blinks 3200 times it indicated one unit consumed so one blink will be equivalent to:

$$
\text { one LED blink }=\frac{1000}{3200} \text { watt hour }
$$

These impressions of the imp/kWh led are captured through a sensor which can be as basic as a Light Dependent Resistor (LDR). LDR is a non-linear device whose sensitivity depends upon the wavelength of light incident on it. Every time the LED blinks the LDR will capture the signal and transfer it to the microcontroller. In the field of the Internet of Things, the most common microcontroller used is Arduino. Arduino Uno is ATmega328 is a low-power high-performance microcontroller; it is used to push the readings recorded through the energy meter into the database. Arduino is an 8 -bit microcontroller that works on operating voltage +1.8 to +5.5 volt. It is preferred due to its cost-effectiveness, robust features, and user-friendly programming. It is connected to a Wi-Fi module. ESP8266 will work as an extension to our Arduino board and will help us connect to the internet. ESP8266 is a cost-effective Wi-Fi microchip. It allows microcontrollers to connect to a Wi-Fi network, using Hayes-style commands it makes a simple TCP / IP connection.

\subsection{Software architecture}

DATABASE is basically a directory where data can be stored. Databases are of two types server based and cloud based. MongoDB is a cloud-based database, and data which we are storing is nothing but the readings from energy meter. The data from the database needs to be displayed on the user's interface. Web sockets are Used for updating real time data on the client side. It plays a prominent part in establishing communication between server and client. WebSocket's play very essential part because they update users' interface without request from the client are using the node.js for programming part. JavaScript is very convenient and easy language to compute and run. Node.js is an open-source cross platform language which can execute the code outside a web browser. It is used for running the program, decoding the program, using command line tools and for server's operation. Node.js let's developer use JavaScript to write command line tools and for server side running script side to produce dynamic web page content before the page is sent to user's web browser. For hosting purpose, we are using Heroku. Heroku is cloud platform as a service supporting several programming languages. Although, choosing a hosting platform is purely a business decision. There are multiple factors involved in choosing a right hosting. For example, vertical scaling, horizontal scaling, pricing etc. 


\section{International Journal of Innovations in Engineering and Science, www.ijies.net}

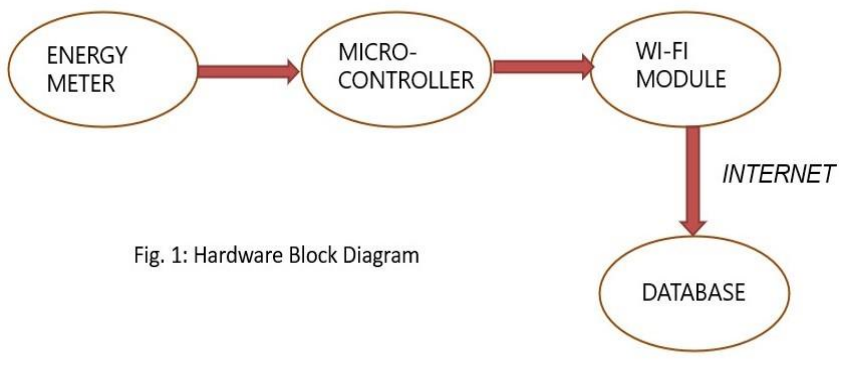

Fig 1: Block Diagram Hardware

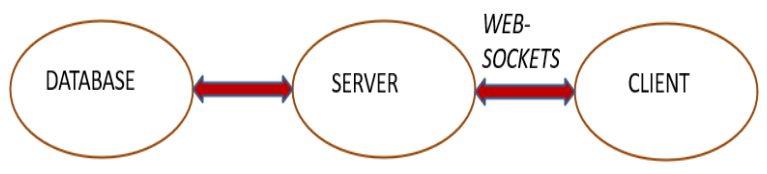

INTERNET

Fig 2- Block Diagram Software Parts

\section{III- RESULT AND CONCLUSION}

\subsection{Result}

The energy consumption monitoring has been done using web-based system. The consumption is done at real time which means when one reading goes up in the energy meter at a certain time of the day the graph goes up at the same time.

The real time readings are listed in the table below:

Table 1-Reading Data

\begin{tabular}{|l|l|l|}
\hline Time (X - Axis) & $\begin{array}{l}\text { Impres } \\
\text { sion }\end{array}$ & $\begin{array}{l}\text { Cumulative } \\
\text { energy } \\
\text { consumption } \\
\text { (kWh) (Y-Axis) }\end{array}$ \\
\hline May 122021 01:00:00 AM & 0.3125 & 0.3125 \\
\hline May 122021 03:30:00 AM & 0.3125 & 0.625 \\
\hline May 122021 05:30:00 AM & 0.3125 & 0.9375 \\
\hline May 122021 08:00:00 AM & 0.3125 & 1.25 \\
\hline May 122021 09:00:00 AM & 0.3125 & 1.5625 \\
\hline May 122021 10:00:00 AM & 0.3125 & 1.875 \\
\hline May 122021 12:20:00 PM & 0.3125 & 2.1875 \\
\hline May 122021 01:00:00 PM & 0.3125 & 2.5 \\
\hline May 122021 03:00:00 PM & 0.3125 & 2.8125 \\
\hline May $12202104: 30: 00$ PM & 0.3125 & 3.125 \\
\hline May $12202105: 20: 00$ PM & 0.3125 & 3.4375 \\
\hline
\end{tabular}

\subsection{Graphical Representation}

The Graphical representation of the energy consumption at the front end is used for better user understanding and analyzing purposes. Pictorial representation is shown in the figure below:

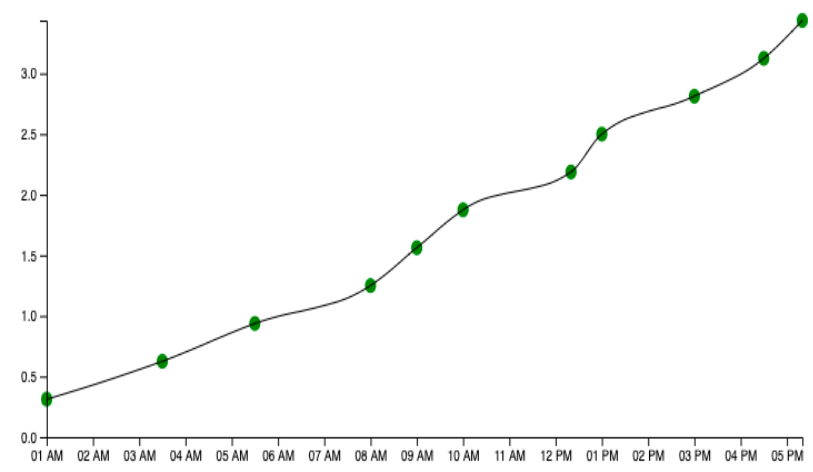

Fig 3: Graphical Representation

\subsection{Conclusion and Future Scope}

It will help consumer to track their daily consumption. Distribution company can directly access the data of electricity consumption through internet and to minimize their electricity consumption.

We can create a specific hybrid application instead of webapp.

We can add access to new facilities such as bill payment directly through app.

Further the addition of controlling home appliances through the app using internet of things is also possible. Future expansion in case of prepaid energy system can also be done through this project.

\section{REFERENCES}

[1] Saldik Yildiz \& Mustafa Burunkaya, "Web Based Smart Meter for General Purpose Smart Home Systems with ESP8266" https://ieeexplore.ieee.org/document/8932931

[2] Md. Masudur Rahman, Noor e Jannat, Mohd Ohidul Islam and Md. Serazus Salakin, "Arduino and GSM Based Smart Energy meter for advanced metering and billing system", 2nd conf. on electrical engineering and information technology 2015 jahagimagar university. 
Vol. 6, No. 2, 2021, PP. 13-16

\section{International Journal of Innovations in Engineering and Science, www.ijies.net}

[3] Petar Radanliev, "Design principles for cyber risk impact assessment from internet of things", University of Oxford.http://iaescore.com/journals/index.

[4] F. Benzi, et al., "Electricity smart meters interfacing the households," IEEE Transactions on Industrial Electronics, vol/issue: 58(10), pp. 4487-4494, 2011.

[5] X. P. Liu, et al., "Guest Editorial introduction to the Focused Section on Wireless Mechatronics," IEEE/ASME Transactions on mechatronics, vol/issue: 17(3), pp. 397-403, 2012.

[6] N. K. Suryadevara, et al., "WSN-Based Smart sensors and Actuator for Power Management in Intelligent Buildings," IEEE/ASME transactions on Mechatronics, vol. 2, pp. 564$571,2015$. 